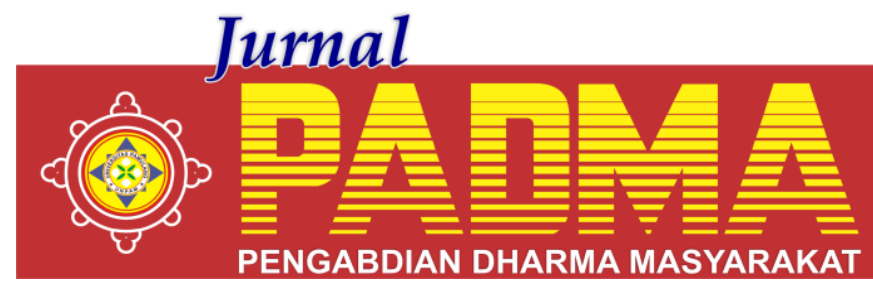

\title{
WORKSHOP FINANCIAL LITERACY UNTUK SISWA SMK SASMITA
}

\author{
${ }^{1 *}$ Kiki Dwi Wijayanti, ${ }^{2}$ Yossy Wahyu Indrawan, ${ }^{3}$ Elizabeth Tika Kristina Hartuti, ${ }^{4}$ Zaenal \\ Abidin, ${ }^{5}$ Ade Yusuf \\ Universitas Pamulang, Tangerang Selatan, Banten, Indonesia \\ *dosen02247@unpam.ac.id
}

\begin{abstract}
Abstrak
Kegiatan ini bertujuan untuk memotivasi serta memberikan penyuluhan bagi anak, khususnya anak dalam usia sekolah (pelajar), agar dapat mengatur keuangan dan bisa memperioritaskan antara kebutuhan primer, skunder, dan tersier. Kegiatan pengabdian ini mengambil tema "Workshop Financial Literacy Untuk Siswa Sma 6 Tangerang Selatan. Beberapa materi pengelolaan keuangan, khususnya untuk siswa yang mendapatkan uang dari pekerjaan sampingan bisa menjadi langkah awal yang tepat untuk dilaksanakan oleh remaja menuju kemandirian ataupun kebebasan finansial atau financial freedomMetode kegiatan pengabdian yang digunakan adalah pendekatan kekinian dengan metode diskusi berkelompok sehingga dapat lebih mudah dipahami oleh siswa SMA 6 Tangerang Selatan yang rata-rata adalah pemuda dan remaja milenial yang up to date dengan keadaan saat ini. Pada metode penjelasan, setiap instruktur menyampaikan materi terkait dan membuat tampilan visual berupa slide power point yang ditampilkan ke layar dengan LCD proyektor.
\end{abstract}

Kata Kunci: Financial Literacy, Financial Freedom

Abstract

This activity aims to motivate and provide counseling for children, especially children of school age (students), in order to manage finances and be able to prioritize primary, secondary and tertiary needs. This service activity takes the theme "Financial Literacy Workshop for Senior High School 6 Tangerang Selatan Students. Some financial management materials, especially for students who get money from a side job can be the right first step for teenagers to take towards independence or financial freedom or financial freedom The method of service activities used is a contemporary approach with a group discussion method so that it is easier for students to understand. SMA 6 Tangerang Selatan, which on average is millennial youth and adolescents who are up to date with current conditions. In the explanation method, each instructor delivers related material and makes a visual display in the form of a power point slide that is displayed on the screen with an LCD projector.

Keywords: Financial Literacy, Financial Freedom

\section{PENDAHULUAN}

Sebagai salah satu SMK Unggulan di Tangerang Selatan, SMK Sasmitha berkewajiban membentuk mindset dan ketrampilan peserta didiknya agar mampu bersaing di era milenial saat ini. Salah satunya adalah dengan mengembangkan skill kewirausahaan para siswa. Agar Siswa dapat memiliki semangat berwirausaha yang terstruktur sejak dini, mampu memetakan diri dan dapat membuat branding diri dan produk yang dibuat

Identifikasi masalah yang ditemukan di lapangan adalah masih banyak siswa merasakan tekanan dalam finansial untuk saat ini dan masa depan. Lebih dari seperempat, atau sekitar 28 persen merasakan banyak kecemasan finansial sehingga berdampak dari kegiatan belajar yang sedang dijalani. Masalah keuangan membuat siswa mengalami stress dan memikirkannya terus-menerus, pola hidup konsumtif pada usaia remaja akan berdampak buruk juga dengan keuangan mereka. Dengan kecemasan yang berlebih, besar kemungkinan siswa malah mengambil keputusan yang salah. Seperti tidak sengaja menghabiskan uang.

Ditemukan masih kurangnya pemahaman dan pengetahuan para remaja khususnya siswa dalam mengelola keuangan mandiri, siswa yang memiliki kegiatan usaha dalam hal mengatur diri dan membuat perencanaan keuangan yang baik. Hal itu 
dikarenakan para anggota mayoritas masih belum memiliki pemahaman dan sikap dalam berorganisasi yang baik. Sehingga diperlukan penyuluhan mengenai pengelolaan keuangan sederhana. Agar siswa dapat megelola keuangan dengan baik, hal itu akan sangat membantu ketika seseorang yang menginjak masa dewasa awal, masa di mana secara psikologis jiwanya masih rentan untuk terpengaruh dan mudah berubahubah, hal utama yang menjadi konstentrasi adalah keuangan bagi para dewasa awal.Mengingat pengeluarannya juga akan besar karena gaya hidup pada masa ini lebih tinggi daripada anak-anak atau orang tua. Remaja yang berada pada masa ini mendapatkan pemasukan dari orang tua atau hasil bekerja. Sehingga harus dapat memanage keuangannnya dengan baik.

Masalah keuangan yang dihadapi siswa adalah pengeluaran lebih besar dibandingkan dengan uang bulanan yang didapat dari orangtua.Sebagai seorang siswa, sudah harus mulai melatih diri untuk bisa mandiri dan bisa mengatur keuangan sendiri tanpa campur tangan orangtua.Akan tetapi, masih banyak siswa yang kehabisan uang jajan sampai harus menahan lapar di akhir bulan.

Uang bulanan pemberian orang tua seringkali tidak bisa mencukupi semua kebutuhan dan memaksa siswa untuk mencari cara (biasanya pinjam uang ke teman) demi bertahan hingga bulan berikutnya. Siswa sangat konsumtif dalam berbelanjan, Tawaran diskon, apalagi dengan skema "potongan pada pembelian kesekian" mendorong seseorang untuk membeli barang-barang yang kurang esensial demi mengejar diskon. Alasannya, "suatu saat akan berguna" atau "kapan lagi dapat barang murah". Padahal setelah dihitung benarbenar-misalnya pada barang "A"-, perbedaan harga setelah mendapatkan diskon dengan sebelum diskon hanya berbeda sedikit saat membelinya satuan. Siswa seharusnya dapat belajar untukk lebij realistis pada jebakan-jebakan diskon yang ditawarkan. Tak lagi menjadi kalap, siswa akan lebih selektif pada barang yang benarbenar esensial, dengan atau tanpa diskon. Agar hal tersebut tidak terjadi, siswa perlu membuat anggaran keuangan dan disiplin mencatat keuangan setiap bulannya.
Sebagian siswa masih berpikir bahwa kegiatan mereka hanya sekadar belajar dan berpartisipasi dalam kegiatan sekolah yang tidak bisa menghasilkan uang.

$\begin{array}{ccc}\text { Manfaat } & \text { Pengabdian } & \text { Keapda } \\ \text { Kegiatan } & \text { Pengabdian } & \text { Kepada }\end{array}$
Masyarakat dari tim dosen dan mahasiswa Universitas Pamulang hadir di SMK Sasmitha dalam bentuk pelatihan. Pelatihan ini akan melakukan pendekatan kekinian dengan metode diskusi berkelompok sehingga dapat lebih mudah dipahami oleh siswa SMK Sasmitha yang rata-rata adalah pemuda dan remaja milenial yang up to date dengan keadaan saat ini.

Beberapa materi pengelolaan keuangan, khususnya untuk siswa yang mendapatkan uang dari pekerjaan sampingan bisa menjadi langkah awal yang tepat untuk dilaksanakan oleh remaja menuju kemandirian ataupun kebebasan finansial atau financial freedom. Hal ini tentu akan bisa didapatkan pada saat sang anak ataupun remaja telah lulus kuliah dan mendapat pekerjaan, atau justru sudah memiliki kehendak bekerja sambilan (part time) saat masih sekolah pun kuliah.

\section{METODE}

Dalam kegiatan ini metode yang diterapkan diharapkan dapat memberikan kemudahan kepada para mahasiswa SMA 6 Tangerang Selatan. Metode yang digunakan adalah metode diskusi kelompok, sharing, tanyajawab, praktik yang di damping oleh pemateri. Pada metode penjelasan, setiap instruktur menyampaikan materi terkait dan membuat tampilan visual berupa slide power point yang ditampilkan ke layar dengan LCD proyektor.

Instruktur dalam menyampaikan penjelasan juga memasukkan unsur "sharing" atau berbagi pengalaman mengenai pengelolaan binis sederhana yang dilakukan oleh siswa dan materi yang telah dimiliki pemateri, dengan pertimbangan tersebut diharapkan dapat memberikan gambaran lebih jelas kepada peserta. Pada metode praktik, peserta berkelompok dan dengan pendampingan panitia mahasiswa bergantian menyusun perencanaan binis secara bergantian berkaitan dengan temannya. Peserta diajarkan bagaiman acara 
menyusun daftar kebutuhan dan mereka diperbolehkan memberikan penambahan daftar keinginan yang ingin mereka capai beserta strategi untuk mencapainya. Dengan demikian siswa tidak hanya sekedarterarah, dengan menggunakan pengelolaan binis sederhana yang jelas.

\section{HASIL DAN PEMBAHASAN}

$\begin{array}{llr}\text { Kegiatan } & \text { Pengabdian } & \text { Kepada } \\ \text { Masyarakat ini berkaitan } & \text { erat }\end{array}$ dengan pengelolaan keuangan pada siswa. Pemahaman akan pentingnya uang haruslah disadari oleh usia remaja, dan sekolah menengah harus bisa membimbing setiap pelajar untuk dapat memahami keuangan dengan baik. Tingkat literasi keuangan yang rendah akan berdampak pada individu dan sosial. Berdasarkan hasil penelitian empiris, remaja yang memiliki tingkat literasi keuangan rendah akan mempunyai perilaku keuangan negatif ketika dewasa misalnya saldo tabungan minus, pembayaran kredit yang terlambat, tidak memiliki asuransi kesehatan dan tidak memiliki dana cadangan keuangan untuk keadaan darurat. Sedangkan, Individu yang mempunyai literasi keuangan tinggi akan lebih tangguh dalam menghadapi guncangan makroekonomi. Ketidakmampuan masyarakat membuat keputusan finansial dapat menimbulkan dampak negatif pada seluruh aspek perekonomian suatu negara. Krisis keuangan dapat dipandang sebagai outcome dari kurangnya kompetensi keuangan dari warga negaranya.

Pendidikan literasi keuangan harus dimulai sejak dini karena jika anak-anak mendapatkan pendidikan literasi keuangan sejak dini, maka mereka kelak akan memperoleh pembelajaran kumulatif. Akan tetapi, saat ini informasi dan pendidikan literasi keuangan bagi remaja sangatlah terbatas, bahkan kurikulum pendidikan di Indonesia belum memasukkan pendidikan literasi keuangan. Di beberapa negara, pendidikan literasi keuangan sudah terintegrasi dalam kurikulum pendidikan dasar. Di China dan India, pendidikan literasi keuangan diintegrasikan dalam kurikulum sekolah. Sedangkan di Selandia Baru pendidikan literasi keuangan didesign sebagai mata pelajaran terpisah. Keseriusan pemerintah China, selandia baru dan India dalam hal pendidikan literasi keuangan berbuah manis, terlihat dari masuknya negara tersebut dalam top performers financial literacy versi OECD. Jika dihubungkan dengan pertumbuhan tingkat pertumbuhan ekonomi, negara top performers financial literacymemiliki pertumbuhan ekonomi terbaik pula, misalnya sepanjang kuartal I-2015, pertumbuhan ekonomi China mencapai 7\%. Sedangkan pertumbuhan ekonomi India sepanjang kuartal I-2015 mencapai 7,5\%. Hal ini menunjukkan warga yang memiliki pengetahuan keuangan yang baik akan berdampak positif terhadap perekonomian bangsa.

Tingkat literasi keuangan dipengaruhi oleh tingkat pendapatan dan pendidikan orang tua. Remaja dari keluarga ekonomi lemah mempunyai tingkat literasi keuangan lebih rendah dibanding remaja dari keluarga ekonomi tinggi. Remaja dengan orang tua yang berpendidikan rendah, memiliki tingkat literasi keuangan yang lebih rendah dibanding mereka dengan orang tua berpendidikan tinggi. Sehingga menyerahkan pendidikan keuangan ke keluarga bukan merupakan solusi, karena tingginya kesenjangan tingkat pendidikan dan tingkat penghasilan di Indonesia.

Perlu adanya upaya untuk mengintegrasikan pendidikan literasi keuangan pada Kurikulum sekolah. Mengapa? Karena sekolah dapat menjangkau semua anak, termasuk mereka yang memiliki kesempatan kecil untuk mengenal literasi keuangan dari luar sekolah. Selain itu, lingkungan sekolah memungkinkan pendidikan keuangan dapat diintegrasikan ke topik lain, seperti matematika, agama dsb. Penelitian menunjukkan bahwa pendidikan keuangan di tingkat sekolah dasar dan menengah memiliki pengaruh yang positif terhadap peningkatan kompetensi keuangan siswa.

Perilaku yang konsumtif sering tak disadari. Alhasil, banyak orang yang begitu konsumtif sehingga perlahan keuangannya menjadi bermasalah. Uang yang diterima mungkin tinggi namun tidak ada yang bisa ditabung di akhir bulan.

Siswa juga harus tahu tujuan Siswa dalam mengalokasikan dana. Bila Siswa tidak bijak dalam menetapkan tujuan 
pembelanjaan, Siswa hanya akan membelanjakan uang Siswa untuk berbagai keperluan yang sebenarnya tidak perlu.

Tak bisa dipungkiri, anak muda memang senang menghabiskan waktu untuk berkumpul/nongkrong, menikmati sesuatu yang sedang tren, berusaha untuk terus sejalan dengan perkembangan terkini dalam berbagai bidang, dan sebagainya. Apalagi bagi siswa yang belum memiliki tanggungan atau masih lajang. Karena belum memiliki tanggungan, ia merasa belum bertanggung jawab untuk mengelola keuangannya karena pendapatannya hanya untuknya. Jadi, anggapan bahwa penghasilannya hanya untuknya seakan melekat dalam dirinya.

Dana darurat tidak hanya permasalahan yang harus dipersiapkan oleh orang akan sangat bermanfaat bila nantinya ada saja ke dewasa. Siswapun memerlukan ini untuk membayar perluan mendadak yang harus dipenuhi sementara uang Siswa tidak cukup untuk menutupinya. Siswa mungkin belum terpikir untuk mempersiapkan dana darurat, atau bila pun sudah terpikir, uang Siswa sudah habis lebih dulu sebelum benarbenar memulai untuk menyiapkan dana darurat.

Solusinya dari sekarang Siswa harus bisa menyisihkan sejumlah uang yang kemudian dialokasikan khusus untuk dana darurat. Misalnya, dalam sebulan, cobalah sisihkan uang saku Siswa per bulan, misalnya 20\% dari gaji Siswa, khusus untuk dana darurat. Nantinya, jangan pernah sentuh uang tersebut selain dari keperluan mendesak.

Menabung juga menjadi salah satu cara mengelola dan membentuk tujuan keuangan yang baik. Katakanlah Siswa berencana menikah di usia 28 tahun.

Tidak Berinvestasi Sehingga Keuangan Habis Begitu Saja Tidak Menghasilkan salah satu masalah keuangan yang sering dihadapi Siswa adalah kurangnya kesadaran bahwa seturut waktu uang yang ia miliki akan berkurang nilainya terutama ketika inflasi terjadi.setiap Siswa kerap mengabaikan fakta bahwa pendapatan hari esok bisa saja lebih rendah ketimbang hari ini.

Maka dari itu demi mempersiapkan diri dari kemungkinan-kemungkinan yang menyesakkan ke depannya, jangan biarkan uang yang Siswa miliki saat ini diam tak menghasilkan.

Siswa bisa mencari sumber penghasilan baru seperti berbisnis atau memulai pekerjaan sampingan. Siswa bahkan bisa berinvestasi terutama karena beragam instrumen investasi.

Dengan pengelolaan keuangan yang mantab, siswa akan lebih bisa fokus dalam belajar, dapat mengatur diri dengan baik, memiliki tujuan yang pasti, serta akan membuatnya mampu berpikir secara rasional. Siswa akan lebih mengenal dirinya sendiri, potensi yang dimiliki serta upaya yang dapat dilakukan untuk meraih keinginannya dan dapat menikmati prosesnya dengan benar.

Group Disscusion yang digunakan sebagai model penyampaian materi dirasa sangat efektif, siswa lebih dapat terbuka dalam menyampaikan keresahannya tentang masa depan dengan suasana yang santai dan terbuka. Mencurahkan permasalahn keuangan yang ternyata tidaklah sederhana yang seperti perkiraan sebelumnya. Seluruh perserta diajak mengutarakan permasalahan untuk kemudian dipecahkan bersama-sama. Kebanyakan siswa yang menjadi peserta masih belum memiliki dasar yang kuat dalam pengelolaan keuangan, sehingga gaya hidup mereka cenderung boros, impulsif dan menjadi generasi milenial yang sangat konsumtif.

\section{PENUTUP}

Hasil kegiatan PKM di SMK Sasmitha berjalan dengan lancar. Siswa terlihat antusias mempelajari materi dalam kegiatan PKM Literasi keuangan, Pendidikan literasi keuangan harus dimulai sejak dini karena jika anak-anak mendapatkan pendidikan literasi keuangan sejak dini, maka mereka kelak akan memperoleh pembelajaran kumulatif. Akan tetapi, saat ini informasi dan pendidikan literasi keuangan bagi remaja sangatlah terbatas, bahkan kurikulum pendidikan di Indonesia belum memasukkan pendidikan literasi keuangan. Di beberapa negara, pendidikan literasi keuangan sudah terintegrasi dalam kurikulum pendidikan dasar.

Tingkat literasi keuangan dipengaruhi oleh tingkat pendapatan dan pendidikan orang tua. Remaja dari keluarga ekonomi 
lemah mempunyai tingkat literasi keuangan lebih rendah dibanding remaja dari keluarga ekonomi tinggi. Remaja dengan orang tua yang berpendidikan rendah, memiliki tingkat literasi keuangan yang lebih rendah dibanding mereka dengan orang tua berpendidikan tinggi. Sehingga menyerahkan pendidikan keuangan ke keluarga bukan merupakan solusi, karena tingginya kesenjangan tingkat pendidikan dan tingkat penghasilan di Indonesia.

\section{DAFTAR PUSTAKA}

Baron-Donovan, C., Wiener, R. L., Gross., K., \& Block-Lieb, S. 2005. Financial literacy teacher training: A multiple-measure evaluation. Financial Counseling and Planning, 16(2), 63-75.

Barsah, A., Sudarso, A. P., \& Sunarsi, D. (2020). Analisis Pengaruh Pengajaran dan Sertifikasi Guru terhadap Kompetensi Guru pada Sekolah Menengah Kejuruan Di Wilayah Parung Panjang Kabupaten Bogor. Journal of Education, Humaniora and Social Sciences (JEHSS), 3(2), 650-657.

Bernheim, B. D., Garrett, D. M., \& Maki, D. M. 1997. Education and Saving: The LongTerm Effects of High School Financial Curriculum Mandates. National Bereau of Economic Research. Working Paper 6085.

Chen, H., \& Volpe R. P. 1998. An Analysis of Personal Financial Literacy Among College Students. Financial Services Review, 7(2), 107-128.

Child and Youth Finance International. 2016. Training Course on: Fostering National Financial Education Strategies. Podgorica: CYFI and GIZ.

Deng, H., Chi, L., Teng, N., Tang., \& Chen, C. 2013. Influence of Financial Literacy of Teachers on Financial Education Teaching in Elementary School. International Journal of eEducation, e-Business, e-Management and e-Learning, 3(1), pp. 68-73.

Dewi, R. V. K., Sunarsi, D., \& Akbar, I. R. (2020). Dampak Penggunaan Teknologi Informasi dan Komunikasi Terhadap Minat Belajar Siswa di SMK Ganesa Satria Depok. Jurnal Ilmiah Wahana Pendidikan, 6(4), 1001-1007.
Hermawati, R., Sugiyarti, L., Handayani, R., Sunarsi, D., Alfiah, S., \& Maddinsyah, A. (2020). The Effect of Trilogy Leadership Style and Organization Culture on School Performance: Evidence form Indonesian Senior High School. PalArch's Journal of Archaeology of Egypt/Egyptology, 17(6), 8512-8537.

Kasmad, K., Mustakim, M., \& Sunarsi, D. (2020). Influences of Price, Promotion, and Service quality on Communities' Interest in Choosing Vocational High School. Journal of Educational Science and Technology (EST), 6(2), 233-243.

Paeno, P., Kasmad, K., Sunarsi, D., Maddinsyah, A., \& Supiyan, D. (2020). Pemanfaatan Sampah Plastik Untuk Kerajinan Rumah Tangga Taman Belajar Kreatif Mekar Sari. Baktimas: Jurnal Pengabdian pada Masyarakat, 2(1), 57-61.

Sampurnaningsih, S. R., Andriani, J., Zainudin, Z. A. B. A., \& Sunarsi, D. (2020). The Analysis of Entrepreneurship Character and Entrepreneurship Intention among Students. PalArch's Journal of Archaeology of Egypt/Egyptology, 17(6), 8290-8303.

Yuangga, K. D., \& Sunarsi, D. (2020). Pengembangan media dan strategi pembelajaran untuk mengatasi permasalahan pembelajaran jarak jauh di pandemi covid-19. JGK (Jurnal Guru Kita), 4(3), 51-58. 